\title{
Income inequality projections for the Shared Socioeconomic Pathways (SSPs)
}

\author{
Narasimha D. Rao ${ }^{1}$, Petra Sauer ${ }^{2}$, Matthew Gidden ${ }^{1}$, and Keywan Riahi ${ }^{1}$ \\ ${ }^{1}$ International Institute for Applied Systems Analysis, Austria \\ ${ }^{2}$ Vienna University for Business and Economics, Austria
}

August 29, 2018

\begin{abstract}
This paper presents global scenarios of future national Gini coefficients, based on an econometric model of the evolution of income inequality within countries over the last three decades. These projections are defined within the scenario framework of the Shared Socioeconomic Pathways (SSP) in climate research, in which income inequality is a qualitative dimension, but not quantified. The projections are driven primarily by total factor productivity (TFP), education attainment at different levels of education, and social public spending. We combine projections of TFP and education from the SSPs and scenarios of public spending with the historical model results to generate Ginis by SSP with uncertainty. The resulting Gini trends across SSPs are distinct and broadly consistent with the SSP narratives. Divergence in Ginis across the SSPs is strongest in emerging economies, and weakest in industrialized countries. The insights from this analysis can enrich the SSP narratives along new dimensions, such as capital and labor income shares and trade.
\end{abstract}

Article Published in Futures, available at doi: https://doi.org/10.1016/j.futures.2018.07.001 


\section{Introduction}

This paper presents global scenarios of future national income inequality, as measured by Gini coefficients ${ }^{1}$, based on an empirical analysis of historical drivers over the last three decades (Rao, Sauer, and Pachauri, 2016) ("RSP2016"). The motivation for this work is to understand how socioeconomic trends, such as income and population, drive global environmental challenges, such as mitigating and adapting to climate change. Income inequality is a defining dimension of the Shared Socioeconomic Pathways (SSP) (O'Neill, Kriegler, Keywan Riahi, et al., 2014) in climate research, which define a spectrum of socioeconomic outcomes for future societies. In previous work, we know of attempts to forecast only between-country income inequality, which focus on the evolution of future national GDP (Crespo Cuaresma, 2017; OECD, 2011). One study combines these GDP forecasts with assumptions of within-country Gini coefficient trajectories to illustrate possible global income distributions in the SSPs (Van der Mensbrugghe, 2015). However, fundamental drivers of inequality within countries are not explicitly examined. So far, income inequality within countries has been only qualitatively developed in the SSP storylines. The distribution of income influences not only how the demand for energy, ecosystem services and greenhouse gas emissions may evolve, but also how population's vulnerability to climate change will be distributed within countries and across the globe. Projections of countries' Gini coefficients can be combined with existing GDP projections to estimate countries' future income distributions and poverty levels. As such, this study start to fill an important need in climate research to better quantify climate change impacts on vulnerable populations across the world (Ruijven et al., 2014). The World Bank develops two scenarios of future poverty levels, but only until 2030, and only for acute poverty (Hallegatte et al., 2016).

The econometric model underlying the projections ("predecessor model") estimates the combined effects on income inequality of the well-known race between technology and education, trade, the labor share of income, and a limited set of policy variables. The complexity of income inequality and the multitude of factors that influence it make the task of developing a comprehensive understanding, let alone that of making future predictions, daunting. Indeed, the predecessor model documents the inconclusive nature of empirical evidence in support of most of the theories advanced towards explaining income inequality, not least because known drivers interact in different ways to produce different outcomes in different societal conditions, many of which are not observed in available global data sets. It is because of this inconclusive landscape of evidence that the predecessor model investigated whether any robust drivers can be found that have a similar pattern of influence across countries on national income inequality. It is only on the basis of the resulting set of determinants that meet this standard that these projections have been developed.

Some of the relevant drivers identified in the predecessor model, namely total factor productivity (TFP) and education (defined below), are quantified dimensions of the SSPs. Therefore, we are able to critique the internal consistency of the SSPs between these drivers and the income inequality storylines with regards to their conceptualization and realization, as reflected in these projections. In the case of other drivers that are not elaborated as yet in the SSP, such as capital and labor income shares, this study provides insights that can be used to fill this gap. Scenarios of future redistributive policies are represented through the mechanism of education and health spending, the former of which is derived from the available SSP quantifications of education attainment. The influence of some fundamental structural drivers related to capital and its concentration, top incomes and related country-specific policies are not captured in this study. As further research quantifies the mechanisms of evolution in top incomes and capital income, these should be incorporated into these projections.

\footnotetext{
${ }^{1}$ The Gini coefficient ranges from 0 (no inequality) to 1 , representing the average difference in income between every pair of members in a group. It can also be derived from the Lorenz curve. See (Sen, 1992)
} 
Overall, we find a high level of consistency between the projections and the SSP narratives. The consistency is greater for developing economies, where technology and education/education policy changes are significant differentiators across SSPs. We demonstrate that despite the parametric uncertainty in the underlying model, income inequality trends across SSPs are distinct. The projections likely underestimate the extent of inequality reduction in the sustainable pathways (SSP1/5) in advanced economies due to the limited representation of redistributive policies in the predecessor model, and gaps in the SSP narratives related to structural changes in capital and labor income.

The rest of the paper is structured as follows. Section 2 starts by summarizing the predecessor model and how its results were used to develop the projections model. The latter part of Section 2 summarizes the characterization of inequality in the SSPs and what one can expect from quantitative trends in within-country inequality. Section 3 presents the set-up of the projections model. Section 4 discusses the results, and Section 5 concludes with some pointers for further research.

\section{Background}

The projections in this study are built on a predecessor model to explain historical within-country income inequality, which is described in detail in RSP2016. We first briefly introduce some of the key theoretical underpinnings of the model, but refer readers to RSP2016 and its references for a detailed review of various theories of income inequality and their supporting empirical evidence. The key features of the model are then reproduced here for convenience, after which we show how it has been used in this study.

\subsection{Theoretical background}

There are several theories that explain the evolution of income inequality (Atkinson and Bourguignon, 2000). However, there is little consensus on how to view them together. At the most fundamental level, income inequality is explained by how returns to capital and labor are distributed across the population, and how capital and labor shares themselves evolve. Public policy can influence the extent of inequality in households' disposable income through taxes, transfers and other mechanisms that influence the above factors.

Among the many factors that affect the distribution of wages, the literature emphasizes the skill-bias induced by technological change and trade, and the equalizing effects of education. Education and the premium associated it, along with indirect effects through trade and technological change affect income inequality through both wages, via its effect on skill premia, and the substitution of capital for labor, which was brought to the fore recently by Piketty (2014). Atkinson (2014) provides a simple modified version of the neoclassical Solow growth model that enables the illustration of these mechanisms, $Y=F\left(K_{1}, A L+B K_{2}\right)$. The model distinguishes between two forms of capital. An increase in the 'traditional' form $\left(K_{1}\right)$ increases the capital income share if labor is easily substituted by capital ${ }^{2}$. In its other form $\left(K_{2}\right)$, capital replaces labor (e.g., robots become competitive) when the ratio of wages to the return on capital is greater than the ratio of labor to capital productivity (A/B), again resulting in increasing capital income shares. If capital income is more unequally distributed than labor income, this results in increasing inequality in the personal income distribution. One can further separate labor $(L)$ into skilled and unskilled labor, and assume technology to only augment the former, to incorporate the inequality-increasing effect of skill-biased technological change along the lines of Acemoglou (2002).

Traditionally, TFP — the residual of growth after accounting for capital and labor inputs in the Solow growth model — has represented productivity improvements from technological change.

\footnotetext{
${ }^{2}$ This is true if the elasticity of substitution between labor and capital is greater than one
} 
However, it has become increasingly apparent that TFP may measure a number of factors other than technological change, including the effect of social institutions (Hall and Jones, 1999) or other inputs not counted in K and L. Furthermore, as illustrated in the model above, the specific effects of technological change would be better represented through the particular mechanisms. Due to data limitations, such as the shares of labor-supporting capital across countries and time, this type of model could not be estimated in this study. In our model, we thus resort to TFP as a proxy for technological change. In any case, that TFP may be a crude measure for a number of mechanisms does not pose a problem, since we do not aim to identify causal mechanisms. Rather, what is important is that it captures forces that influence inequality other than those that we explicitly account for in our model, such as education, trade and the capital/labor share.

The empirical evidence of TFP's effect on within-country income inequality is scant. Roser \& Cuaresma (2014) find the interaction of TFP and education to have a significant effect on income inequality in OECD countries, with education having an equalizing effect on inequality to a greater extent at low TFP levels. In the predecessor model, we find evidence for the positive effect of TFP on inequality, which is robust to a number of model specifications that vary the regional scope and the inclusion of additional drivers, such as foreign direct investment (FDI). RSP2016 also investigates various forms of non-linearities, and found robust evidence for an interaction between TFP and public education spending.

\subsection{Underlying historical model}

The predecessor model estimates the Gini coefficient $\left(I G i n i_{t}\right)$ as a linear combination of explanatory variables, which include total factor productivity $(T F P)$, education attainment at different levels $(\mathbf{E})$, non-resource trade $(\mathbf{T})$, the labor share of income $(L)$, and policy variables $(\mathbf{P})$, including political orientation $(P O)$ and public spending (PS) on education, health and social services. Education attainment at a given level (primary, secondary and tertiary) is the share of the population above the age of 15 that has only that level of education. Non-resource trade includes the GDP shares of imports from high- and low-income countries and exports. In each case trade in natural resources (e.g. oil) is excluded. Political orientation represents the political ideology of the chief executive's party, as an increasing score from 1 to 3, indicating right, center and left, respectively. This measure is taken from the World Bank's Database of Political Institutions. It is intended to represent the structure and extent of public social provisions and of progressive taxation and labor market policies. The specification of the model is as follows:

$$
\text { IGini }_{t}=\beta_{1} T F P_{t-1}+\beta_{2} \mathbf{E}_{t-1}+\beta_{3} \mathbf{T}_{t-1}+\beta_{4} L_{t-1}+\beta_{5} \mathbf{P}_{t-1}+\gamma Y e a r+\alpha_{i}+\epsilon_{i, t}
$$

with

$$
\begin{aligned}
& \mathbf{E}=\text { Education }:[\text { primary }, \text { secondary }, \text { tertiary }] \\
& \mathbf{T}=\text { Trade }:[\text { high }-/ \text { low }- \text { incomeimports }, \text { exports }] \\
& \mathbf{P}=\text { Policy }:[\text { PO, } \mathbf{P S}]
\end{aligned}
$$

The model was estimated based on global panel data for the period 1980-2010. In order to account for different preceding historical conditions, country fixed effects $\left(\alpha_{i}\right)$ were included. A time variable $(Y e a r)$ was necessary to de-trend the model, because several explanatory variables were found to be trend stationary. That is, with a number of variables varying similarly with time, the model is only able to discern the effect of each variable around the time trend. This is the main reason why the model is not a comprehensive predictor of the Gini. As discussed later, the time trend is indeed significant and necessary to include in the projections. We interpret this as a 
proxy for unobserved structural trends. As such, in certain scenarios we would expect its influence to diminish with time.

A unique feature of the predecessor model is also the dataset on which it is based. As described in RSP2016, the authors used the World Income Inequality Database (WIID v3.0B, September 2014), and developed selection criteria to ensure that, as far as possible, sources are based on a consistent set of measures and assumptions, and of a minimum quality. Furthermore, time series of income Gini coefficients were included only if they had a minimum of three time observations over one decade. Observations with data for only a single year as well as observations which were unreasonably inconsistent with data from other sources were excluded. More often than not, the data sources used were: the Luxembourg Income Study (LIS) and Eurostat measures for Western European countries, Transmonee (UNICEF) for countries in transition, the Social and Economic Database for Latin American Countries (SEDLAC) for Latin American countries, and either individual country or World Bank sources (Deininger and Squire, or the Poverty Monitoring Database) for Asian and African countries.

Numerous model specifications and sensitivities were examined to test the robustness of the predictors, including the inequality measure (an extreme decile ratio), alternative data sources (e.g. for TFP and the Gini), the use of interaction terms, and the inclusion of other variables with less geographic coverage, such as top income shares. Readers are referred to RSP2016 for details.

\subsection{Model selection for projection}

With the numerous model specifications in RSP2016, our primary decision criterion for selecting a model for projections was model fit. We calculated the Bayesian Information Criterion (BIC), which can be used to compare different model specifications, with lower values indicating a better model fit. However, we had other considerations that precluded us using BIC as the sole criterion. We applied these additional considerations as prior constraints, after which we relied primarily on the BIC. For instance, since we want to undertake global projections, we rely on the global models, even though some specifications for advanced economies yielded better fits. We also pick variables that were generally robust. For instance, we prefer the model specification with political factors, which generally has better model fits than those without, with a few exceptions. Finally, we use the OECD TFP source, which has the soundest conceptual basis (because it includes energy resources in the growth model) and yields the lowest BICs among the TFP sources. For further details, see the SI and RSP2016. All subsequent discussion of the predecessor model in the projections refer to this specification ("projections model"), whose results are discussed in Section 4.

\subsection{The SSP storylines and income inequality}

Part of the motivation of this exercise is to assess the internal consistency of the SSPs between the socioeconomic drivers of income inequality and the qualitative aspects of income inequality themselves. Thus, before presenting the projections, we first recap how income inequality has been envisioned in the SSPs and then describe our expectations of the projections based on the findings of the predecessor model and the related projections of drivers in the SSP storylines.

The SSPs were developed for the climate change research community in order to characterize future scenarios of societal conditions in terms of the challenges they present for climate change mitigation and adaptation (O'Neill, Kriegler, Ebi, et al., 2015; K. Riahi et al., 2016). Notably, the SSPs do not attempt to incorporate climate change impacts to which we are already committed, or to any committed climate policies. The SSPs capture long-term uncertainties in societal change, including trends within countries. As described by O'Neill, Kriegler, Keywan Riahi, et al. (2014), the development of SSPs is intended to be carried out in two stages. The basic five SSPs were the first to be developed based on extensive expert consultation, which resulted in the selection of 


\begin{tabular}{lccccc} 
Variable & SSP1 & SSP2 & SSP3 & SSP4 & SSP5 \\
\hline $\begin{array}{l}\text { Inequality Between Advanced } \\
\text { and Developing countries }\end{array}$ & Low & Med & High & Med-Hi & Low \\
Inequality within countries & Low & Med & Med-Hi & High & Low \\
$\begin{array}{l}\text { Drivers (Inequality within Countries) } \\
\text { TFP Frontier }\end{array}$ & Med & Med & Low & Med & High \\
TFP Convergence(+) & High & Med & Low & Low-Med & High \\
Education(-) & High & Med & Low & Hi Tert;Low Prim/Sec & High \\
Social Policy(+/-) & High & Med & Low & Low & High \\
Labor Income Share (-) & - & - & - & - & - \\
Non-resource Trade $(+/-)$ & - & - & - & - & - \\
\hline
\end{tabular}

Sources: Income inequality from O'Neill, Kriegler, Keywan Riahi, et al., 2014, education from KC and Lutz, 2014, TFP from Dellink et al., 2015, social policy by authors.

$(+/-)$ indicates direction of influence of driver on income inequality in the predecessor model.

Table 1: Summary of the representation of income inequality and its key drivers in the SSP narratives.

certain elements of definition, including demographics, economic development and its distribution, non-economic welfare dimensions (such as education and health), environmental and ecological factors, technological change, governance and institutions, non-climate policies, and other societal factors, such as lifestyles. Some of these dimensions have already been quantified, including a number of demographic variables, such as population growth, urbanization, and education attainment (KC and Lutz, 2014; Jiang and O'Neill, 2014), and GDP (Crespo Cuaresma, 2017; Dellink et al., 2015). Other characteristics, including income inequality, have been qualitatively described. The basic SSPs aim to describe broad categories of story lines, within which more nuanced variants may well be defined.

Notably, the SSP narratives include projections of key socioeconomic variables, such as education and economic activity, which are known to influence income inequality, but which have not necessarily been viewed from this perspective in the SSPs. For example, technological change and the capital share of income are integral components of GDP and its projections, both of which we have seen are drivers of inequality. Similarly, education advancements can influence income inequality in either direction, depending on its distribution and quality. Based on our understanding from the predecessor model and the socioeconomic aspects of the SSP narratives, we make some additional observations on the expected differences in national Ginis across the SSPs. The upper part of Table 1 summarizes the representation of income inequality between and within countries in the SSPs, while the lower half qualitatively describes the characterization of relevant socioeconomic drivers of income inequality in the SSP narratives, including TFP, education, and social policy. The other drivers that have been found to be significant in the predecessor model, namely labor share of income and non-resource trade, have not (as yet) have been quantified in the SSP storylines (see Section 2.2).

SSP1 is the 'Sustainability' pathway, which presents relatively low challenges to climate mitigation and adaptation, and a commitment towards inclusive growth and human well-being, such that inequality both across and within countries is expected to decline. We would therefore expect this scenario to have lowest levels of Ginis from among the SSPs. Given that income inequality has increased in most countries in the last few decades, a world heading towards SSP1 would reverse historical trends in the vast majority of countries. To achieve these outcomes would likely require a significant boost in policy efforts towards reducing inequality globally, through mechanisms such as investments in basic education, health, and the social net on the one hand, and possibly taxes 
on high incomes and capital gains on the other. Notably, technology investments would continue, particularly those that reduce resource intensity. However, in order that they not cause a net increase in income inequality, they would either not lead to the skill-bias associated with general technological change, or if they did, these effects would have to be more than offset by equitable social policies.

SSP3 represents the other extreme, in which societies would face high challenges for both climate mitigation and adaptation. These simultaneous challenges would result from material-intensive development and high poverty, due to limited attention to broad-based human and technological development. Income inequality is expected to increase, particularly between countries, due to regionalism, conflict, and weak global institutions. The extent of income inequality within countries is not given as much attention in SSP3 as in SSP4. In SSP3 high levels of poverty are envisioned, a large share of which lies in emerging economies today. Since overall economic growth, albeit lower than the other SSPs, still occurs, taken together, these trends would imply some divergence, and hence growing within-country income inequality, at least in a limited set of emerging economies with high absolute emissions and extreme poverty.

SSP2 is the "middle of the road" scenario, which, in terms of climate mitigation and adaptation challenges, would fall in between SSP1 and SSP3. This scenario reflects the lack of any major transformations that would affect either GHG emissions or adaptation challenges, such as in technology or global institutions. This scenario has been presented as an extrapolation of recent historical trends with regard to some socioeconomic aspects, such as population and economic growth. The elements of this scenario have not been developed with any nuance, other than in relation to the other SSPs. Judging them based on past trends alone, one would expect that income inequality would continue to increase at a modest pace, as it has in the last several decades in most countries. However, there may be scope for regional variations in income inequality within this 'middle-of-the-road' scenario. For instance, European and emerging economies such as China could reduce inequality through policies that shifted income growth from the top to the middle class without significantly reducing poverty. This could alter income distributional trends more than it would global levels of both economic output and poverty, thereby keeping the world on the same trajectory of mitigation and adaptation challenges.

SSP4 is characterized by high inequality, due to stratification across and within countries. Economic growth in the developing world is suppressed so that global emissions are relatively low but climate adaptation challenges remain high due to high poverty. In this pathway a global elite is envisioned in which power, knowledge and capital is concentrated. Developing societies remain labor-intensive, and poor, except for local elites that presumably live in 'bubble' economies. This is a dystopic vision, with the highest expected projections of inequality among all the SSPs. This scenario would likely entail low policy efforts towards basic human development, and low sharing of the gains in economic productivity in the developing world. Notably, technological development is globally stronger in SSP4 than in SSP3, which is consistent with higher inequality. However, to the extent that overall TFP influences the quality of public social spending, and given that tertiary education is expected to get more attention in SSP4 than in SSP3 (See Table 1), education spending can have an equalizing effect on inequality in some countries in SSP4. On balance, although according to the storyline SSP4 has higher within-country income inequality, the expectation from the underlying drivers is less clear.

In SSP5, climate adaptation challenges are low, due to high, equitable, technology- and capitalintensive growth, but powered by fossil fuels, thereby leading to high global GHG emissions. Global markets and institutions are increasingly integrated, leading to technology transfer, and economic surpluses are invested in human and social capital, and presumably the management of environmental systems to stem their degradation. This scenario would seem to achieve many dimensions of sustainability, as with SSP1. As such, one would expect a number of transformative shifts towards redistributive policies compared to today, and therefore similar trends in income 


\begin{tabular}{lcccc}
\hline Variable & Unit & Coefficient (sd) & Sample Mean & Sample Std Dev \\
\hline TFP & $(2005=1)$ & $8.5^{* * *}(2.6)$ & 0.93 & 0.14 \\
Educ-Prim & \%pop & $-0.27^{*}(0.15)$ & 27.8 & 17.7 \\
Educ-Sec & \%pop & $-0.26^{*}(0.14)$ & 50.1 & 17.3 \\
Educ-Tert & \%pop & $-0.61^{* * *}(0.20)$ & 16.4 & 8.9 \\
Imp-HiSkill & \%gdp & $0.05^{* *}(0.02)$ & 23.6 & 14.1 \\
Imp-LowSkill & \%gdp & $-0.12^{* *}(0.06)$ & 0.01 & 0.03 \\
LabShre-Inc & \% & $-0.09^{*}(0.05)$ & 58.2 & 8.4 \\
PubSp-Health & \%PubSp & $-0.07^{* * *}(0.02)$ & 10.2 & 4.5 \\
PubSp-Educ & \%PubSp & $0.67^{* * *}(0.18)$ & 11.9 & 5.8 \\
TFP*PubSp-Educ & - & $-0.61^{* * *}(0.19)$ & 11.3 & 6.3 \\
Year & year & $0.26^{* * *}(0.07)$ & - & - \\
\hline
\end{tabular}

Table 2: Summary of key drivers and model estimates. Education variables are shares of population above 15 yrs.

inequality between SSP1 and SSP5.

\subsection{Interpreting the historical model}

Understanding the relative effects of the drivers in the predecessor model on the evolution of the country Ginis requires knowing both the sign and magnitude of the coefficients, and the historical magnitude and trend of the drivers themselves. Table 2 shows the results for the significant drivers, including their mean and standard deviation over the sample, and the estimated coefficient. The product of the coefficient and the standard deviation gives an idea of the relative impact, in absolute terms, of each variable on the Gini. The direction of the impact, however, depends on the historical trend in each variable.

TFP is the main variable that increases income inequality. In general, TFP is projected to increase (see Section 3) to different extents in the SSPs, so we expect TFP to be the main inequalityincreasing driver in the SSPs. The time trend, as discussed, likely reflects structural trends that are not reflected in the dataset, but which have increased inequality. Education attainment at all levels reduces inequality, which is the main driver having an equalizing effect on income inequality. An interesting finding is that the effect of education spending is mediated by TFP, which makes the inequality-reducing effect of this public spending increase with higher TFP (and only set in above a certain level). At very low levels of TFP, education spending increases inequality. We interpret this as an efficacy or quality of education spending. Trade has mixed effects of relatively low impact, and has in any case not been quantitatively assessed as yet in the SSPs.

The combined effect of these drivers, taking into account both their expected correlation with inequality and their projected direction under each SSP gives a good qualitative indication of the different income inequality outcomes across SSPs described above. For instance, In SSP1 and SSP 5 the combination of both strong investments in education and progressive social policy would be expected to outweigh the inequality-increasing effect of TFP increases, and the converse would be the case with SSP3. However, in SSP4, despite an expectation of high inequality, its position relative to SSP3 is less clear, since the effects of both TFP and education are not as strong as in SSP3, as discussed further below. 


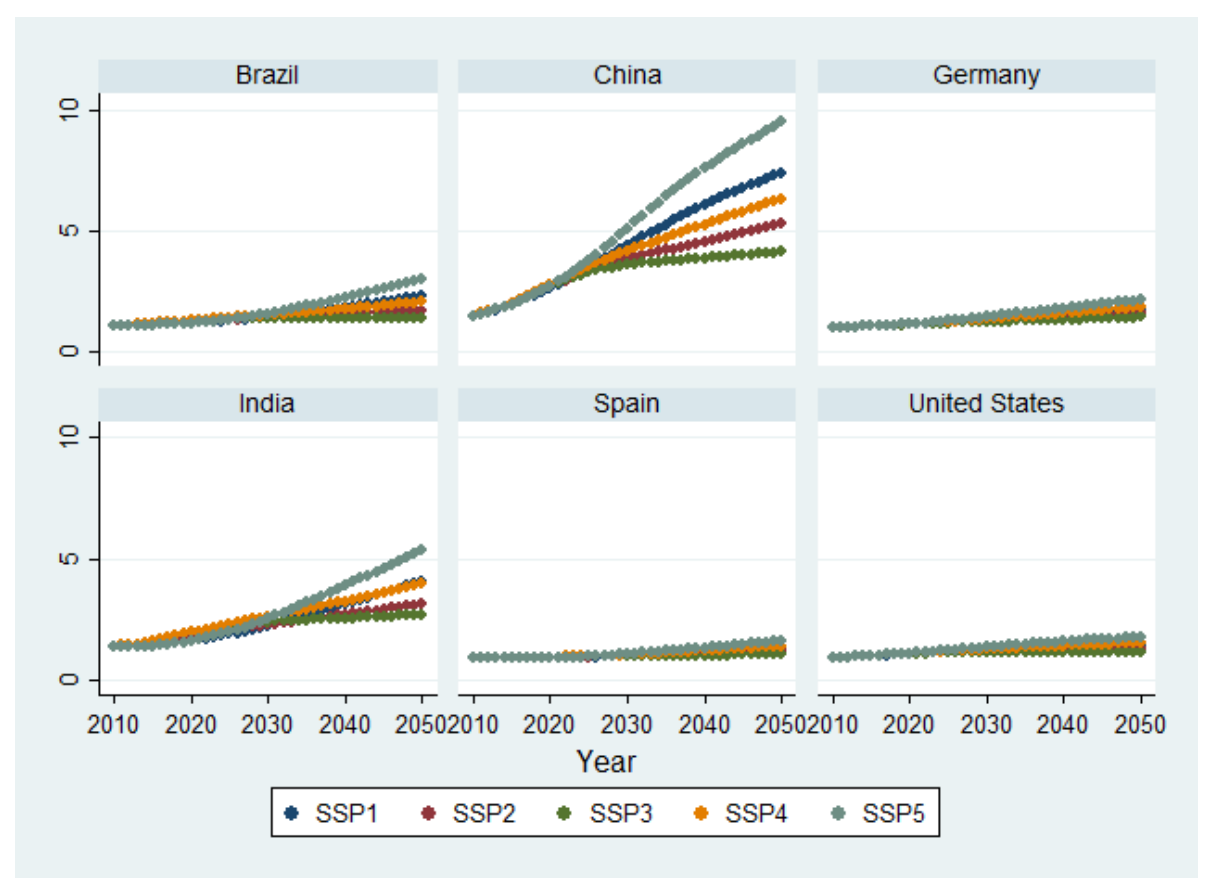

Figure 1: TFP Projections for Select Countries by SSP (Source: authors' rendition of data provided by OECD, from (Dellink et al., 2015)). TFP units relative to $2010(2010=1)$.

\section{Income inequality projections - Set Up}

\subsection{Key drivers and their projections}

The predecessor model provides the coefficients for explanatory variables in the projections model. The sum-product of these coefficients and the projections of their corresponding explanatory variables are used to project the income Gini, as per Equation 1. The country fixed effect is required to calibrate the Gini to its historical levels. As discussed in Section 2.4, among the explanatory variables, only TFP (from OECD), and education (attainment levels from IIASA) have projections in the SSP storylines thus far. The dynamics of the evolution of the Gini shown henceforth largely reflect the opposing effects of these two variables. All other significant variables are held constant at an average of the five most recent values (2005-2010), including the trade variables and the labor share of income. The Year variable is significant, and possibly captures the effect of unobservables, whose significance diminishes further into the future, as discussed in Section 3.2.2.

The projections of the main drivers, TFP and education, are shown in Figure 1 and Figure 2. Overall, TFP increases in all countries, but at different rates in different SSPs (see Table 1). Moreover, TFP growth is highest in SSP5 and SSP1, and lowest in SSP3. TFP growth rates are highest in emerging economies, and lowest in mature, industrialized economies. Education attainment differences across the SSPs manifest most strongly in tertiary education across all countries. The contrasting trend in lower education manifests in either primary or secondary, depending on countries' different starting points. Less developed countries show more divergence in primary attainment between SSP1 and SSP3, for example, while more developed countries show greater differences in secondary attainment. 


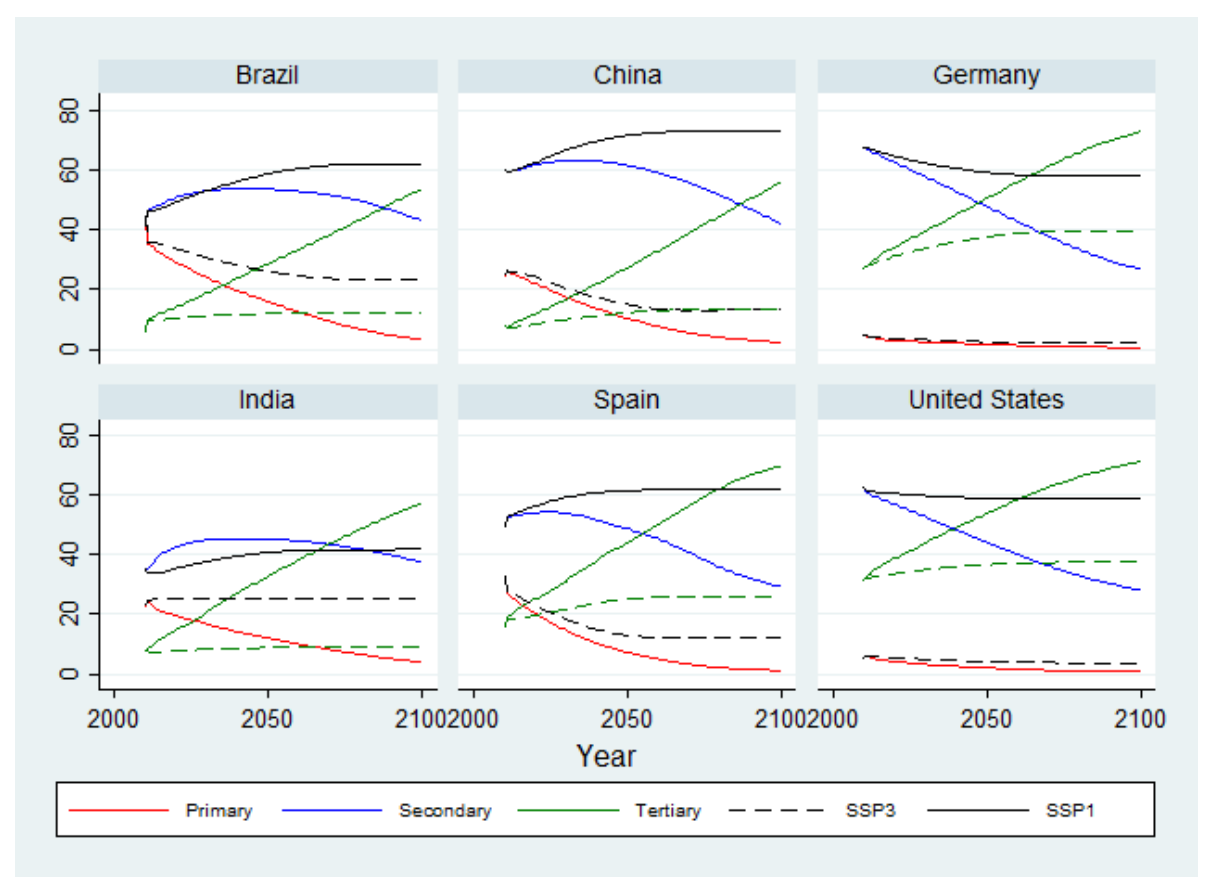

Figure 2: Education Projections for SSP1 (Source: (KC and Lutz, 2014)). Units are shares of population (percent) above 15 yrs.

\subsection{Policy scenarios}

The predecessor model offers a limited empirical base from which to formulate policies with distributional effects in SSPs. In RSP2016, several indicators of policy - such as public spending on health, education and social security; political orientation; and labor market institutions - were tested. Significant results were found only for public spending on health and education (see Table 2 ), due in part to the lack of sufficient data for the other variables.

\subsubsection{Education and health spending}

We introduce a projection for education and health spending for the SSPs. For public spending on education, we create three indices of change, to represent three likely drivers of changes in future education costs: the total educated population (population index); the shares of population in each level, each of which has different costs (level index); and the average resources per student (resource index). Each index is calculated as a multiple of the base year (2010) value for any future year. The product of these indices are multiplied by the current (2010) education spending to generate a future time series. The population and level indices are derived from the education attainment projections in the SSP storylines, so as to make the scenarios of public spending consistent with the outcomes (attainment) in the projections. The weights for the respective costs of education in the level index are based on relative costs for OECD countries (OECD, 2014). These two indices are applied to all countries.

The resource index reflects the difference in priority accorded to education in public spending. The average share of public spending is below the global average, and rates of growth of spending are well below that of GDP for many countries. For instance, in 2010 India and the United States spent approximately 0.5 percent $(\$ 15)$ and 0.9 percent (\$373) of GDP (PPP per capita) on 
education, in contrast to China, which spent about 3 percent $(\$ 213) .^{3}$

We apply the resource index only in SSP1 and SSP5 to countries whose resources were below the global mean in 2010. In SSP1 and SSP5, we would expect a break from past trends and a specific commitment to human capital. The population and level index only capture incremental shifts in spending to reflect changing demographics. However, the imperative to introduce transformational changes in education spending would be stronger at very low levels of spending. For these countries, we increase their average spending annually at the rate of the historical increase in average per capita resources globally, or about 0.1 percentage points per year. This has a fairly modest effect relative to the other two indices, particularly in developing countries and emerging countries that are expected to see large shifts towards higher level education.

Health spending has a direct inequality-reducing effect. Since there are no directly relevant drivers in the SSP storylines, for SSP1 and SSP5 only, we estimate a spending index similar to the resource index for education spending. That is, only for countries with health spending (as a share of total public spending) below the global average, we increase their spending at the rate of the average global increases in the last thirty years, which is also about 0.1 percentage points per year. ${ }^{4}$

\subsubsection{Other policies}

Public spending is only one of several levers available to governments to pursue redistributive policies. Considering that the predecessor model under-represents policies and reveals a steady trend of increasing structural inequality over the last thirty years, as represented in the time trend, under at least some scenarios of societal progress, one would expect that such trends would not continue unabated without countervailing redistributive policies.

We therefore introduce a second policy lever to represent a general inclination towards progressive policies to rectify historical inequities. This objective is convenient to formulate as a decay function of the time trend itself. In keeping with the story lines, we apply the fastest decay (by 2050) to SSP1/5, and phase it out over a longer duration (by 2075) in SSP2. We allow the trend to continue in SSP3 and SSP $4 .{ }^{5}$ This lever has a relatively minor effect on overall inequality (see Table 2) compared to education spending, due to the effect of TFP on the latter in later years.

\subsection{The world after 2050}

These projections are based on the implicit premise that historical structural and macroeconomic relations continue into the future, even if the direction of individual components changes, sometimes even drastically (e.g., SSP1). The presence of path dependence and institutional inertia support this approach. Beyond 2050, particularly in scenarios that assume transformative change, this model cannot offer any basis for such structural shifts. Thus, we provide scenario projections beyond 2050, but with the caveat that these are less reliable.

Based on past history and theoretical limits of the Gini, we expect Ginis to be bounded in the long run. In the past thirty years, actual reported Ginis in our dataset fall within 18 and 66 . Milanovic estimates that the Gini in the United States is unlikely to exceed $60 .^{6}$ We accordingly impose asymptotes of 15 and 65 on the projections where necessary. This is necessary in only a handful of countries in SSP1 and SSP3/4 after 2050.

\footnotetext{
${ }^{3}$ Data on per capita education spending from SPEED (Statistics of Public Expenditure for Economic Development), International Food Policy Research Institute.

${ }^{4}$ See Supplementary Materials for further details.

${ }^{5}$ In year $t$, decayed time variable $T=T_{0}+\left(t-T_{0}\right) * \exp \left(-\left(t-T_{0}\right) / K\right)$, where $T_{0}=2010$, and $\mathrm{K}=\mathrm{decay}$ duration.

${ }^{6}$ See http://glineq.blogspot.co.at/2015/12/a-note-on-maximum-us-inequality.html. Based on the highest observed capital income ratios and typical returns on capital and labor.
} 


\subsection{Inequality of what: income or consumption expenditure?}

Most global datasets on income inequality rely on a mix of data sources, which utilize different income concepts. Generally, Ginis for countries in Asia and sub-Saharan Africa are based on consumption expenditure, while the rest of the world uses some measure of income (which may be disposable (net), gross, or market income). Many countries that have income data also have consumption expenditure data, making it possible to compare them. From previous literature, it is well known that income Ginis are significantly higher than consumption expenditure Ginis (Rao, Sauer, and Pachauri, 2016; Jenkins, 2015; Lahoti, 2015). ${ }^{7}$ However, as far as it has been studied, the trends of each over time are similar.

In keeping with the state of knowledge, the predecessor model, on which these projections are based, implicitly assumes that both expenditure-based and income-based Ginis evolve in a similar manner. However, each country's time series is based on either income or expenditure. As a practical matter, the data are available primarily for countries with income-based Ginis, which likely drive the results of this model.

\subsection{Regional Scope}

The projections are based on an empirical model that is global in scope but limited to 44 countries due to data availability ,including from North America and Europe, Central Asia/Europe, Central and South America, the Middle East, South Asia and East Asia and the Pacific. These countries together comprise 50-60 percent of global population and 60-70 percent of global GDP. See Supplementary Materials for a full listing.

In order to have a complete set of projections for the SSPs, we estimate Ginis for the other countries based on the premise that the relative position of countries' Ginis (reflecting their relative proclivity towards equitable policies) within a broader group remains roughly the same over time, though to different degrees across the SSPs. Countries projected by the model are divided into two groups - industrialized and developing countries. These estimations are done using a quantile regression. The base-year distribution of Ginis for all countries are divided into quartiles. Countries for which model projections exist are used to define future values of quartile means. Each other country's Gini values are derived based on the weighted sum of its relative position in the base year such that it maintains its relative position in the distribution in future years. Projections are performed separately for developing and industrialized countries. ${ }^{8}$

\section{Income inequality projections - Main Results}

Figure 3 shows the Gini projections for a set of countries representative of different regions under all the SSPs. The results reveal primarily the interaction between TFP and education projections, and between the structural trend in the predecessor model and the constructed policy variables. The results are relatively intuitive, in that inequality changes with the SSPs as expected (and discussed in Section 2).

There are some exceptions to the above trends that are insightful of the underlying dynamics. SSP4 consistently has higher inequality than SSP3, except in the case of China, where in the long run SSP3 and SSP4 have similar levels of inequality. This is because of the dual role of

\footnotetext{
${ }^{7}$ Deininger and Squire have suggested that one should add 6 percentage points to the expenditure Gini to make it equivalent to income (Deininger and Squire, 1996). However, exceptions reveal wider differences. Authors estimate the Indian income Gini to be 0.56 compared to its expenditure Gini of 0.34 using the India Human Development Survey (2004-05).

${ }^{8}$ Industrialized country definitions are taken from the Global Energy Assessment (GEA); see GEA Table 17.A2 for further details.
} 
TFP in influencing inequality - while its fundamental effect is to increase inequality, it also has an equalizing effect through its effect on the quality of education spending. In SSP4, this latter effect takes over the former, because of higher investments in tertiary education in many countries (see Figure 2).

India and China, in particular, have noteworthy similarities and differences. In the long term, both converge to similar growth rates of TFP and education levels, but start at very different levels of both. Public spending today on education is an order of magnitude lower in India (3\% of public spending) than in China (12\% of public spending). Even in a transformative world (SSP1/5), without a significant boost in its average expenditure on education, India's Gini would not decline in the long-term, due to the upward push from strongly increasing TFP. China, on the other hand, would see a significant reduction in its Gini in SSP1 due to its above-average investment in education.

Figure 4 shows the median Gini by region under $\operatorname{SSPs} 1,2$ and 3. In the 'business as usual' SSP2, income inequality is expected to increase in all regions, except Latin America, where Ginis are already at high levels. Notably, there is globally more scope for a reduction in future inequality than an increase - given that we are in a trend of increasing inequality. That is, the difference between SSP2 and SSP3 is less in all regions than that between SSP1 and SSP2. A shift to a more equitable world will require a significant shift in social policies and increased public spending on human capital, including health and education, in order to counter historical structural inequalityincreasing trends.

There are also regional differences. In developing economies, the divergence in inequality across SSP scenarios is higher than in the advanced economies. This reflects the fact that the key drivers of this model - technology and education - are not significant enough drivers of inequality in the developed economies. There is higher scope for variation in human capital development and TFP growth in developing economies. Projections of labor income share, or further enhancements to the model related to representing top incomes, for instance, would show greater influence. Notably, in many developed countries, including Germany and the United States, even in SSP1 Ginis slightly increase. This is because the equalizing effect of TFP through education spending is low relative to TFP's independent inequality-increasing effect.

\subsection{Uncertainty in projections}

RSP2016 presents a detailed robustness analysis that verifies the statistical significance and direction of impact of the drivers to changes in data sources, model specification and regional disaggregation. In Section 2 above we discussed the rationale for the chosen model among the set examined in the predecessor model. Here, we focus on the uncertainty in the magnitude of the relative effects that remains after these choices. We present two contributions to uncertainty in the projections: a sensitivity to the use of a single source for Ginis of any country instead of allowing multiple sources, but subject to all other data integrity checks (see Figure 5); and an estimate of the forecast intervals for the Ginis arising from uncertainty in the estimated coefficients in the predecessor model (see Figure 6). We calculated the latter using a stochastic simulation of Equation (1) using random draws from the set of distributions defined by the standard deviations of the Beta coefficients. We present a range of $+/$ - one standard deviation (or 69 percent confidence), illustrated for SSP1 and SSP4 for India.

The results show that the change in data source has a relatively small effect. Substantively, allowing multiple sources produces less aggressive long-term projections, due primarily to lower coefficients on the TFP variables.

The forecast intervals are relatively large, but similar across SSPs and countries. More importantly, despite the relatively high parametric uncertainty, the SSPs depart notably, particularly 


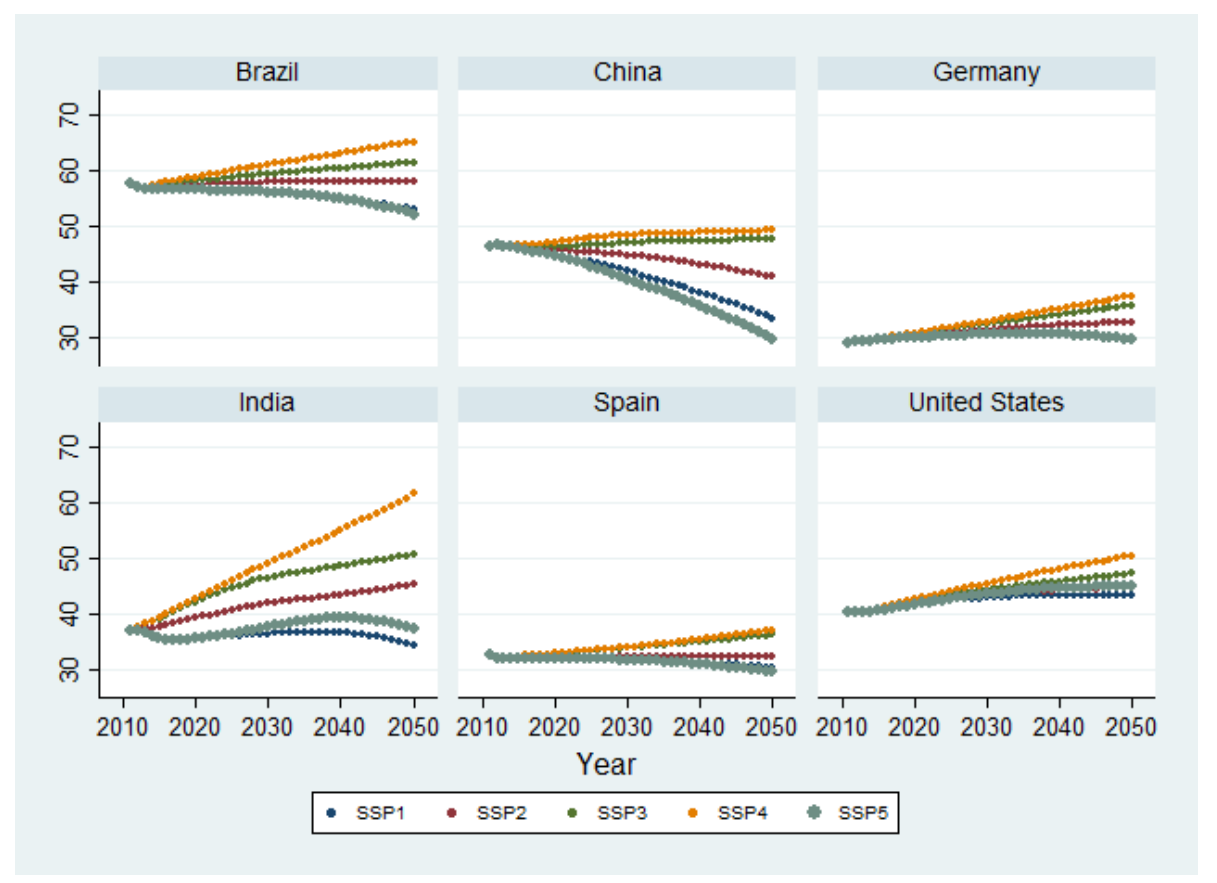

Figure 3: Gini Projections under SSPs - Select Countries

SSP1/5 against SSP3/4, and particularly post 2030. This finding vindicates the use of scenarios to characterize future evolution of socioeconomic conditions. 


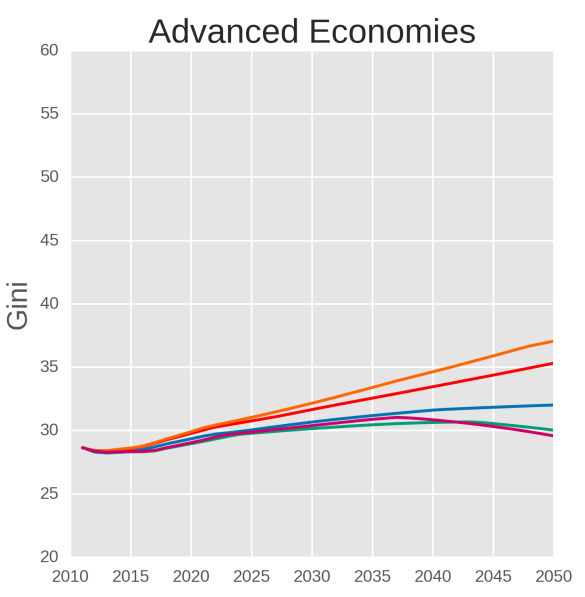

Eastern Asia \& the Pacific

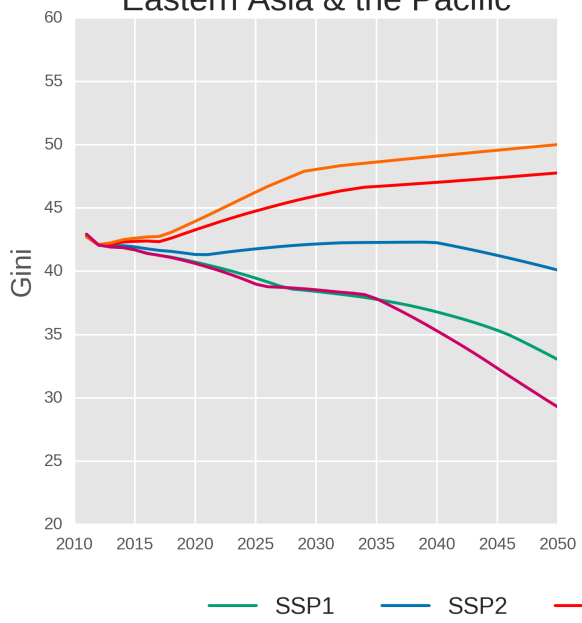

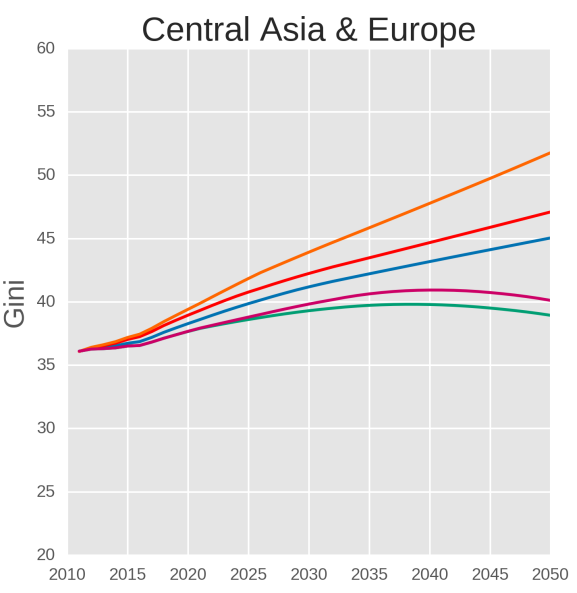

Latin America \& Caribbean

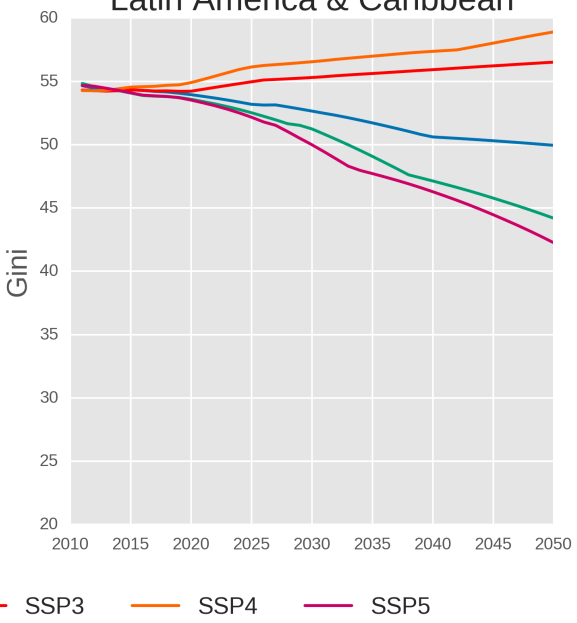

Figure 4: Regional median Gini trends for SSPs 


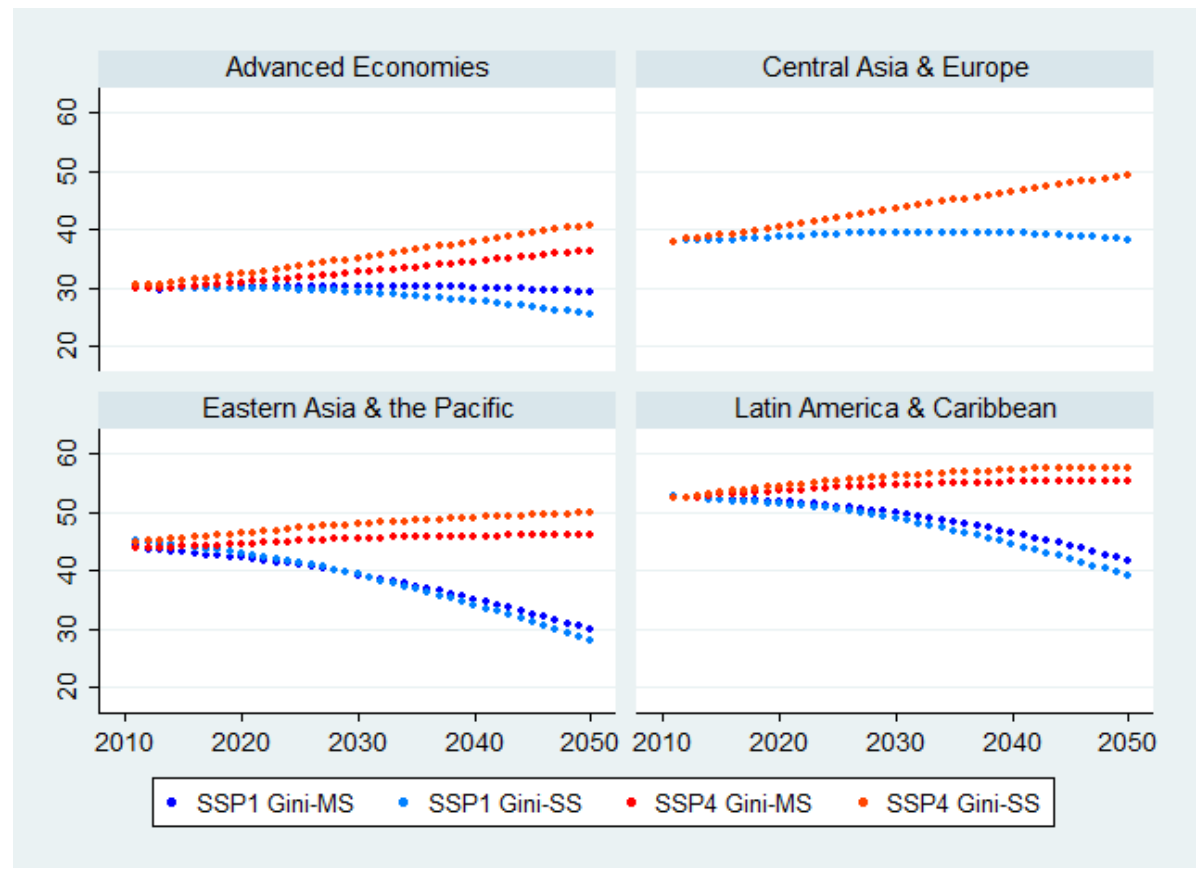

Figure 5: Sensitivity of Gini projections to historical data sources for Ginis. East Asia includes India. SS: Single Source; MS: Multisource. See Section 2.2. 

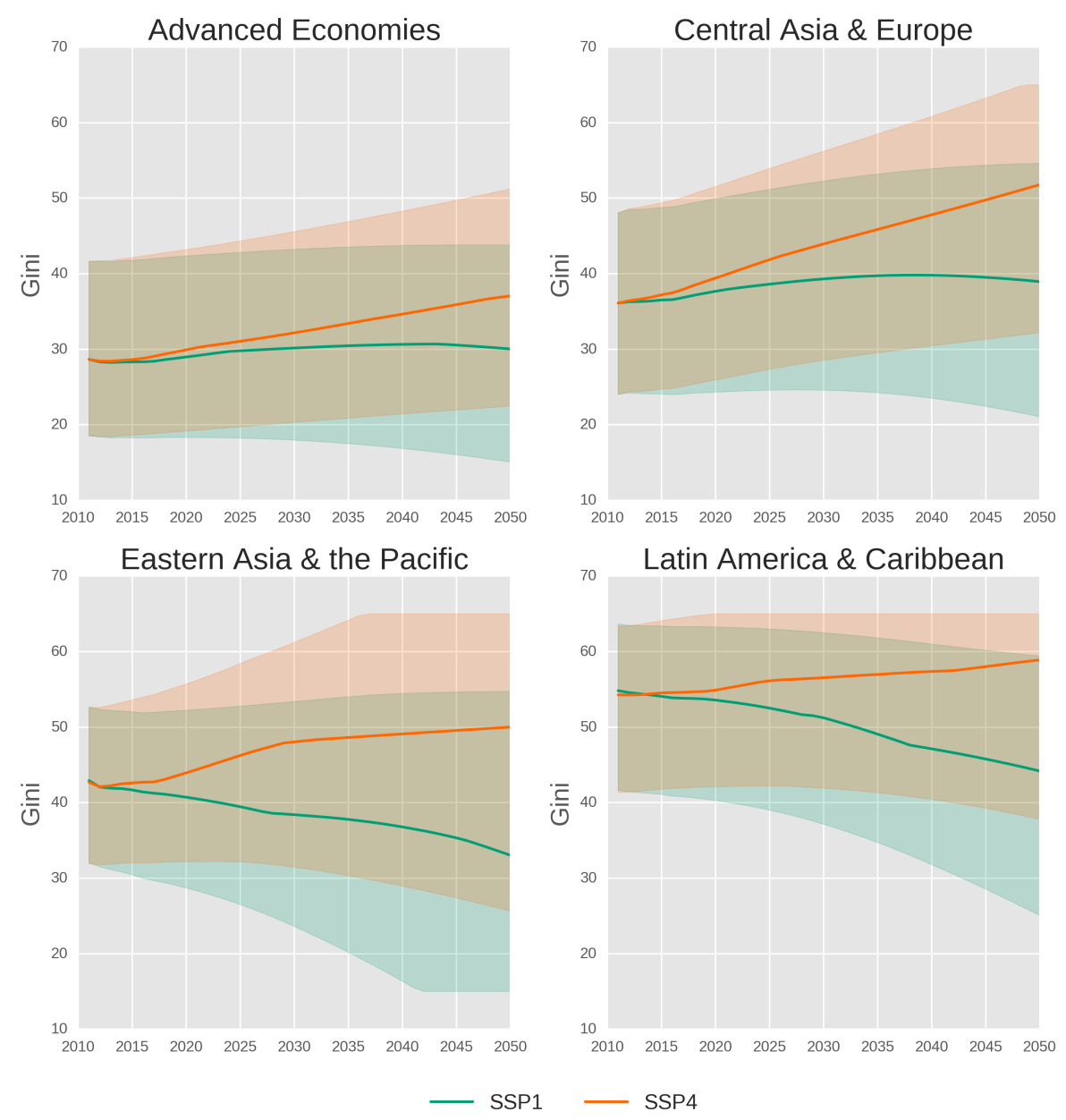

Figure 6: Illustrative forecast intervals for the Gini. +/- one standard deviation for each world region. 


\section{Discussion and future work}

This study presents the first global set of income inequality projections for the SSPs based on a historical econometric model of interactions between technology, education, trade and policy. Besides enriching the SSPs by generating plausible quantitative estimates for the evolution of income inequality, this study also provides a test of internal consistency in the SSPs. The projections by and large affirm that the dynamics of how TFP and education evolve to influence inequality match the outcomes expected in the qualitative story lines. These dynamics play out in developing regions to a greater extent, where changes in TFP and education composition are more extensive in different SSPs. This study also shows that much more would be needed to be done beyond social spending to redress inequality in SSP1/5 in developed regions.

There are limitations to the projections that stem from model and data limitations or from gaps in the quantifications of drivers in the SSP. The predecessor model yielded few indicators of redistributive social and tax policies, which would be important particularly in developed countries to represent future equitable growth. This study has offered some suggestions for filling the gap related to education and health polices. Data limitations on the structural aspects of inequality related to top incomes and wealth accumulation led to these aspects being omitted from the predecessor model and in turn from the projections. Some drivers identified in the predecessor model, such as the labor income share and trade, had to be held constant in the projections due to the absence of projections for them in the SSP narratives. The labor share of income is often an output in integrated assessment based on computable general equilibrium models, though the extent to which labor share is endogenous varies widely across models. Future research into the flexibility of these models to accommodate labor share projections would benefit studies of future income inequality. This study offers some insights on how these drivers would be expected to evolve under different SSPs, which may in future research be used to enrich the SSP narratives further. These are important areas for further research.

Despite these caveats, this study offers a starting point from which to estimate future income distributions and poverty levels in different futures. Of most value is the relative difference in the Ginis in different SSPs and how these differences vary by region, given their different stages of development in technology and education. Researchers of climate change impacts and vulnerabilities can use these projections to characterize future social heterogeneity, and the distributional impacts of adaptation and mitigation policies in different parts of the world. Researchers should be mindful when using these projections to consider the relevance and additive effect of other social policies and omitted macroeconomic aspects discussed above. A further step, though distant, would be to incorporate the income effects of climate change impacts that are already expected.

\section{References}

Acemoglu, Daron (2002). "Technical Change , Inequality and the Labor Market". In: Journal of Economic Literature 40.1, pp. 7-72.

Atkinson, A. B. (2014). "After Piketty?" In: British Journal of Sociology 65.4, pp. 619-638. ISSN: 14684446. DOI: $10.1111 / 1468-4446.12105$.

Atkinson, A. B. and François Bourguignon (2000). "Introduction: Income distribution and economics". In: Handbook of Income Distribution. Ed. by A. B. Atkinson and François Bourguignon. Vol. 1, pp. 1-58. ISBN: 9780444816313. DOI: 10.1016/S1574-0056(00)80003-2.

Crespo Cuaresma, Jesús (2017). "Income projections for climate change research: A framework based on human capital dynamics". In: Global Environmental Change 42, pp. 226-236. ISSN: 09593780. DOI: 10.1016/j.gloenvcha.2015.02.012. 
Deininger, Klaus and Lyn Squire (1996). "A new data set measuring income inequality". In: World Bank Economic Review 10.3, pp. 565-591.

Dellink, Rob et al. (2015). "Long-term economic growth projections in the Shared Socioeconomic Pathways". In: Global Environmental Change, pp. 1-15. ISSN: 09593780. DOI: 10.1016/ j . gloenvcha.2015.06.004.

Hall, Robert E and Charles I Jones (1999). "Why Do Some Countries Produce So Much More Output Per Worker Than Others?" In: The Quarterly Journal of Economics 114.1, pp. 83-116. ISSN: 00335533, 15314650.

Hallegatte, Stephane et al. (2016). Shock waves: Managing the impacts of climate change on poverty. Tech. rep. Washington D.C.: World Bank. DOI: 10.1596/978-1-4648-0673-5.

Jenkins, Stephen P. (2015). "World income inequality databases: an assessment of WIID and SWIID". In: The Journal of Economic Inequality 13, pp. 629-671. ISSN: 1569-1721. DOI: 10. 1007/s10888-015-9305-3.

Jiang, Leiwen and Brian C. O'Neill (2014). "Global urbanization projections for the Shared Socioeconomic Pathways". In: Global Environmental Change. ISSN: 09593780. DOI: 10.1016/j . gloenvcha.2015.03.008.

KC, Samir and Wolfgang Lutz (2014). "The human core of the shared socioeconomic pathways: Population scenarios by age, sex and level of education for all countries to 2100". In: Global Environmental Change. ISSN: 09593780. DOI: 10.1016/j.gloenvcha.2014.06.004.

Lahoti, Rahul (2015). "I . The Central Problem : Lack of Meaning". In: pp. 1-28.

OECD (2011). Divided we stand: why inequality keeps rising. OECD Publishing. ISBN: 9789264119536.

- (2014). Indicator B1: How much is spent per student. Tech. rep. OECD Publishing.

O'Neill, Brian C., Elmar Kriegler, Kristie L. Ebi, et al. (2015). "The roads ahead : Narratives for shared socioeconomic pathways describing world futures in the 21st century". In: Global Environmental Change July, pp. 1-46. ISSN: 0959-3780. DOI: 10.1016/j.gloenvcha.2015.01. 004.

O’Neill, Brian C., Elmar Kriegler, Keywan Riahi, et al. (2014). "A new scenario framework for climate change research: the concept of shared socioeconomic pathways". In: Climatic Change 122.3, pp. 387-400. ISSN: 0165-0009. DOI: $10.1007 / \mathrm{s} 10584-013-0905-2$.

Piketty, Thomas (2014). Capitalism in the 21st century, p. 452. ISBN: 9780674430006.

Rao, Narasimha D., Petra Sauer, and Shonali Pachauri (2016). "Explaining income inequality: an integrated approach". INEQ Working Paper Series; WU Vienna University of Economics and Business. Vienna.

Riahi, K. et al. (2016). "The shared socioeconomic pathways and their energy, land use, and greenhouse gas emissions implications: An overview". In: Global Environmental Change, pp. 138. DOI: $10.1016 / \mathrm{j} \cdot$ gloenvcha.2016.05.009.

Roser, Max and Jesus Crespo Cuaresma (2014). "Why is Income Inequality Increasing in the Developed World?" In: Review of Income and Wealth June, n/a-n/a. ISSN: 00346586. DOI: 10.1111/roiw. 12153.

Ruijven, Bas J. van et al. (2014). "Enhancing the relevance of Shared Socioeconomic Pathways for climate change impacts, adaptation and vulnerability research". In: Climatic Change 122.3, pp. 481-494. ISSN: 0165-0009;1573-1480. DOI: 10.1007/s10584-013-0931-0.

Sen, Amartya K. (1992). Inequality reexamined. Clarendon Press.

Van der Mensbrugghe, Dominique (2015). "Shared Socio-economic pathways and global income distribution". 